\title{
EL PENSAMIENTO LITERARIO ILUSTRADO EN INGLATERRA
}

Isabel NAVAS OCAÑA

Universidad de Almería

Durante este período se producirá una profunda transformación en los estudios literarios. El intelectual ilustrado, aunque acata con frecuencia las reglas clasicistas, prefiere justificarlas no tanto a partir de la autoridad grecolatina como de la razón, de la naturaleza. Surge entonces un nuevo tipo de discurso, la crítica literaria, definido "por oposición a la Poética", ya que pretende someter a 'examen racional' sus principios tradicionales (Wahnón, 1991: 48). Esto no significa que esos principios se cuestionen en exceso. Pero sí se les intenta buscar una explicación más acorde con la naturaleza del ser humano. No en vano se ha afirmado que "la crítica europea moderna nació de la lucha contra el Estado absolutista", como "espacio de juicio racional" ajeno a la arbitrariedad de la política autoritaria (Engleton, 1984: 11). Por eso, el viejo concepto de Poesia se verá ahora incapaz de explicar variedades discursivas, como la novela o la tragicomedia, que la tradición aristotélica no contemplaba, pero que habían estado presentes en la práctica literaria desde tiempo atrás. La Poesía se transforma entonces en Literatura. El genio natural empieza a ser valorado muy por encima de los modelos y se le llega incluso a relacionar con las libertades políticas. John Dennis, Pope, Lord Kames y Johnson son quizás los mejores representantes de esta nueva situación.

Además, el renovado interés por los estudios filosóficos, gracias a la confianza en la razón, provocó el surgimiento de la estética como disciplina independiente. En Inglaterra, la estética alcanza durante el XVIII un desarrollo notable, con nombres tan célebres como Shaftesbury, Addison, Hume, Burke, etc. Las discusiones en torno a la belleza, a los principios universales del gusto, a lo sublime, ocupan un lugar destacado en las controversias de la época.

Por otra parte, la retórica sigue extendiendo sus alas sobre el dominio literario. Aún continúa siendo una fuente indispensable para el conocimiento de las teorías literarias. Así lo evidencian las obras de Hugh Blair o de George Campbell. 


\section{La Estética inglesa del siglo XVIII}

\subsection{Shaftesbury, el moralista}

Anthony Ashley Cooper, conde de Shaftesbury (1671-1713), se ocupó de cuestiones estéticas en muchos de sus ensayos, aunque quizás los más significativos sean An Inquiry Concerning Virtue or Merit y The Moralist'. Para Shaftesbury, la belleza es forma, proporción y armonía eterna. El knowing o well-knowing man percibe primero a través de los sentidos (fundamentalmente la vista y el oído) las bellezas naturales, pero ba de elevarse a un estadio superior, el de la belleza moral de las acciones, la belleza del bien, para alcanzar por fin la belleza suprema: Dios. Sólo así logrará el verdadero goce estético. Para designar este último grado de lo bello, utiliza a menudo los términos 'forma interior', 'ritmo interior' o 'idea'. Evidencia así la ascendencia platónica de sus teorías (Bayer, 1961:220). Pero es quizás el componente moral, tan acusado, lo más característico de la estética de Shaftesbury. Explicará, por ejemplo, la teoría del drama en Grecia desde un punto de vista religioso (relaciona el escenario con el púlpito) y asimilará la tragedia a la apología de la virtud (Ibid.: 222). Belleza y Bien son, por tanto, nociones intercambiables. Se les unirá la Verdad, añadiendo el realismo como principio estético: "La belleza natural en el mundo es la honestidad, la verdad moral: pues toda belleza es verdad. (...) Los rasgos verdaderos son los que hacen la belleza de un rostro, y las verdaderas proporciones la belleza de la arquitectura, así como las medidas verdaderas crean las de la armonía y de la música. En la poesía, que es fábula toda ella, la verdad también es la perfección" (apud Bayer, ibid.: 231).

El buen gusto y el sentido común, conceptos fundamentales de la estética ilustrada, van a estar también impregnados de moralismo. Según Shaftesbury, nos hacen concebir juicios correctos pero no sólo en el campo estético, sino también en el moral. De hecho, nos proporcionan una visión inmediata de lo verdadero y lo honesto, y en consecuencia de lo bello. Por eso, su procedimiento ha de ser el examen de conciencia. Además no debemos confundirlos con la opinión común ni con la modn. Habrín que oponer, por tanto, la generalidad del gusto a la rectitud del gusto (Ibid.: 258).

En cuanto al genio, Shaftesbury distingue entre el simple y natural de la Antigüedad y el genio que procede del estudio de los maestros (Ibid.: 268).

' Raymond Bayer cita además los siguientes: I, Sensus communis, an Essay on Freedom of Wit and Humour (1709), Soliloquy or advice to an author (1710), A notion of the historical draught or tablature of the judgment of Hercules (1712), A letter sent from laly with notion of the judgment of Hercules (1712), A letter concerning design (1713) (1961: 217). 
En esta distinción, que en realidad recoge la dualidad horaciana de ingenitum lars, se percibe, sin embargo, una cierta inclinacion hacia las dotes naturales, hacia el genio espontúneo y libre de los tiempos antiguos, que anuncia ya la veneración romántica por los primitivos.

Pero hay otro elemento de la teoría de Shaftesbury que preludia también el romanticismo, su insistencia en la libertad, condición indispensable para que el artista pueda crear y para que la cultura se desarrolle: "El espiritu de la nación se ha hecho cada vez más libre y ahora nuestro gusto por la música va más allá del refinamiento de nuestros vecinos los franceses, mientras que hace todavía poco tiempo ocurría todo lo contrario. Nuestro oído y nuestro juicio van progresando"' (Ibid.: 248).

\subsection{Addison y los placeres de la imaginación}

On Pleasures of Imagination (1712) de Joseph Addison (1672-1719) es uno de los ensayos más significativos de la estética ilustrada ${ }^{2}$. La consideración de los placeres de la imaginación como estéticos se sitúa en el origen de las teorías sobre lo sublime, el gusto, el genio, etc., de autores tan destacados como David Hume, Edmund Burke y el mismísimo Kant (lbid.: 255).

Los placeres de la imaginación surgen, según Addison, de los objetos visibles. La vista es para él el único sentido estético. Estos placeres son distintos a los que proceden del entendimiento (más fríos) y de los sentidos (más groseros). Y emanan de tres fuentes, que son las fuentes de toda emoción estética: la grandeza, la singularidad y la belleza. La impresión que en nosotros producen las cosas grandes puede explicarse por la configuración especial de nuestra naturaleza, que sólo halla la felicidad con la contemplación de la magnitud divina. La estética de Addison, como la de Shaftesbury, le otorga un lugar de honor a la moral religiosa. Además define lo sublime en intima conexión con lo grande: "parece referirlo al instinto de libertad que se encuentra halagado por los amplios horizontes y por las soledades del cielo y del Océano" (Menéndez Pelayo, 1883-1891, I: 1046). Se vislumbra aquí la concepción romántica de la naturaleza, que también podremos apreciar en otros escritores ilustrados como Hugh Blair.

En cuanto a la singularidad, las cosas novedosas provocan un placer estético que proviene de la inclinación natural al conocimiento, a la indagación, al saber. La belleza, en fin, también es capaz de suscitar el placer en nuestro ánimo, pero lo hará gracias al deleite que experimentamos con la variedad de colores, la simetría y la proporción de las partes o la disposición y ordena-

'El texto de Addison lo tradujo al castellano José Munárriz en Variedades de Ciencias, Literatura y Artes (vol. IIl, 1804). 
ción de los cuerpos. Los colores son quizás el origen de un mayor agrado. Por eso, Addison recomienda que la poesía, al no ser un arte visual, emplee para salvar esta dificultad muchos epítetos de color.

E] gusto también se relaciona con los placeres de la imaginación. Addison lo define como "la facultad del alma que discieme las bellezas de un autor con placer y las imperfecciones con disgusto" (ad Bayer, 1961: 257). Las impresiones del gusto son inmediatas, espontáneas, y por ello se aproximan a los placeres de la imaginación que nacen de la vista.

Para ilustrar estas teorias, Addison recurrirá a los escritores de la Antigüedad. A Homero, por ejemplo, le concede la cualidad de lo sublime, a Virgilio la belleza y a Ovidio la singularidad. Sin embargo, es un autor moderno quien logra todos sus elogios. Sólo John Milton ha conseguido reunir la grandeza, la belleza y la novedad. El canon avanza, por tanto, hacia un escritor inglés. Este hecho ya es significativo como germen del romanticismo. Pero será sobre todo su reivindicación de la antigua mitología céltica (hadas, genios, etc.) lo que le aproxime más al XIX (Menéndez Pelayo, 1883-1891, I: 1048). De todas formas, en su noción de genio también se perciben atisbos que podríamos llamar prerrománticos. Al igual que Shaftesbury, Addison distingue dos tipos de genio: aquéllos que sin estudio y sin arte han logrado obras excelsas y aquellos otros que han sometido su talento natural a las reglas. Addison opta decididamente por los primeros: "la imitación de los mejores autores no puede compararse a un buen original"(apud Bayer, 1961: 267).

\subsection{Hutcheson o el desinterés estético}

An Inquiry into the Original of Our Ideas of Beauty and Virtue (1725) de Francis Hutcheson (1694-1746) ha sido considerado como "el primer tratado regular sobre estética escrito en inglés" (Wellek, 1954-1996, I: 129). A diferencia de Addison, Hutchenson no cree que la percepción de la belleza dependa de la vista, sino de un sentimiento o sentido interior, que podemos identificar con el gusto. Se trata de una facultad natural que "es anterior a la costumbre o a la educación" y consiste en "recibir las ideas de la belleza a la vista de los objetos en los que la uniformidad se encuentra unida a la variedad" (apud Bayer, ibid.: 259). Hutchenson admite por ello la relatividad del gusto, aunque la compensa con el sentido común: cada ser humano podrá asociar de forma individual esas dos cualidades externas de los objetos (uniformidad y variedad) pero todos poseen ciertas ideas como la semejanza, Ia analogía, la proporción, la variedad, etc. Resulta curiosa la insistencia de Hutchenson en que estas ideas son innatas y que no se adquieren mediante la educación o la costumbre. Pero lo cierto es que el énfasis de los intelectuales ilustrados en las dotes naturales pone las bases y allana el camino para la teoría romántica del genio. 
Ahora bien, Hutchenson, buen discipulo de Shaftesbury, debía otorgarle un lugar importante a la moral en su sistema estético. El resultado de la interrelación ética / estética va a ser, sin embargo, insospechado, convirtiéndose en la nota más original del pensamiento de Hutchenson. Como Shaftesbury, Hutchenson parte de la identidad del sentido moral y del sentido estético. Ambos poseen carácter universal y son algo innato, no aprendido. Pero lo más importante: nada tienen que ver con lo útil, el desinterés les caracteriza. Según Hutchenson, "Una bondad natural inmediata en las acciones llamadas virtuosas nos lleva a percibir alguna belleza en los actos de los otros y a amar a quienes los ejecutan, sin miramiento alguno a la utilidad que pueda resultar para nosotros" (apud Bayer, ibid.: 225). Igual ocurre con "el placer que recibimos de la regularidad de un objeto o de la armonía de un concierto, sin tener conocimiento alguno de matemáticas, y sin entrever en ese objeto o en esa composición ninguna utilidad diferente del placer que ella nos procura" (apud Bayer, ibid.: 226). Hutchenson formula con una lógica aplastante la teoría del desinterés estético a partir del desinterés moral. Prepara así el camino a la estética kantiana. Gracias a él, y por supuesto a Kant, en el moralismo clasicista del XVIII empieza a germinar la semilla del arte por el arte.

\subsection{Hogarth y la linea ondulada}

En la estela de Addison, William Hogarth (1697-1764) publicó un Analysis of Beauty (1753), que continúa también las reflexiones de Pope sobre el genio natural. Hogart se decanta por la imitación de la naturalezá antes que por los modelos de la Antigüedad. Pero quizús se le recuerde mäs por sus reflexiones en torno a la linea ondulada, que enlazan con algunos planteamientos del griego Hesíodo en La Teogonía. A propósito de los placeres de la imaginación, Hogart dirá que la "línea de la belleza" es la ondulada, porque responde al movimiento natural del ojo: "que la línea serpentina, con su balanceo y contoneo en diferentes direcciones, conduce al ojo plácidamente a lo largo de la continuidad de su variedad" (1753: 67)'. Ya Hesíodo habiá elevado a canon estético la ondulación, al ser rasgo característico de uno de los más hermosos elementos de la Naturaleza: el mar (Bayer, 1961: 22). Por tanto, Hogart, como los antiguos griegos, como algunos de sus contemporáneos (Pope, por ejemplo) va a buscar el canon de la belleza en la Naturaleza.

Intentará, además, evitar las intromisiones de la moral en el dominio estético, convencido, como Addison, de que lo bello es un atributo de los objetos. Se aplicarả entonces en el análisis de aquellas cualidades objetivas que origi-

'Cito por la edición española de Miguel Cereceda, editada por Visor en 1997. 
nan la belleza: la variedad, la uniformidad, la regularidad o simetria, la sencillez o distinción, la complejidad, la cantidad, la línea ondulada, la línea serpentina, etc. Se convierte así en precedente inmediato del ensayo de Edmund Burke, Philosophical Inquiry into the Origin of the Sublime and Beautiful, que aparecería unos años más tarde. De hecho. Burke confiesa: "No me place poco ver que puedo reforzar mi teoría en este punto mediante la opinión del muy ingenioso $\mathrm{Sr}$. Hogarth, cuya idea de la belleza creo extremadamente justa en general" (apud Cereceda, 1997: 20). El Analysis of Beauty influyó además en Diderot y en el Luocoonte de Lessing (Ibid.).

\subsection{La norma del gusto de David Hume}

Of the Standard of Taste (1757) y Of Tragedy (1757) son quizás los dos ensayos de estética más importantes de David Hume (1711-1776)4. Hume parte de una idea fundamental: "La belleza no es ninguna cualidad de las cosas mismas. No existe más que en la mente de quien la contempla" (apud Wellek, 1954-1996, I: 130) y, por tanto, "Todo sentimiento es correcto, porque el sentimiento no tiene referencia a nada fuera de sí, y es siempre real en tanto un hombre sea consciente de êl" (1757: 27)'. Este tipo de belleza procede de la imaginación y no de los sentidos, y supone una generalización del placer o de la pena a través de la simpatía, que nos permite penetrar en los sentimientos de los demás (Mirabent, 1927: 253). En esta noción de simpatía fundamenta también Hume su teoría de la tragedia: "La visión, o al menos la imaginación de las grandes pasiones que surgen de grandes pérdidas o ganancias, afecta al espectador por simpatía, le hace partícipe de las mismas pasiones y le sirve para un momentáneo entretenimiento" (1757:67).

Ahora bien, sólo sentiremos como bello un objeto cuando sea adecuado a su fin. En la estética de Hume cabe también la utilidad. Lo que ocurre es que esta idea de la adecuación se convierte en un fin en sí mismo: una casa puede parecernos adecuada a su fin, y en consecuencia bella, independientemente de que alguna vez llegue a ser habitada (Bayer, 1961: 234). Volvemos al desinterés estético de Hutchenson. Obsérvese cómo el relativismo o subjetivismo radical del gusto que Hume proclama al definir la belleza como una facultad del sujeto independiente de las cualidades externas de los objetos, queda contrarrestado por tres conceptos de orden general o común: la adecuación, la utilidad y el desinterés. Existirän, por tanto, "reglas generales de la belleza" que se derivan "de modelos ya establecidos y de la observación

' Puede consultarse la edición espan̄ola de María Teresa Beguiristáin, publicada con el título La norma del gusto y otros ensayos por Ediciones Península en 1989.

s Cito por la edición de Maria Teresa Beguiristáin. 
de lo que agrada o desagrada" (Hume, 1757: 34$)^{6}$. A estas reglas ha de someterse la poesía. De la relatividad del gusto hemos pasado a la defensa de principios neoclásicos. Por eso, Hume añade: "Si algunos escritores negligentes o irregulares han conseguido agradar, no lo han hecho por sus transgresiones de las reglas o del orden, sino a pesar de esas transgresiones. Han poseído otras bellezas que eran aceptables por una crítica correcta, y la fuerza de estas bellezas ha sido capaz de superar las censuras y de dar a la mente una satisfacción superior al desagrado que surge de los defectos" (Ibid .: 29).

Para ejemplificar esta idea, plenamente clasicista, Hume recurre a Ariosto: "Ariosto agrada, pero no por sus ficciones monstruosas e inverosimiles, por su grotesca mezcla de estilos serios y cómicos, por la falta de coherencia de sus historias, ni por las continuas interrupciones en su narración, sino que cautiva por la fuerza y la claridad de sus expresiones, por la prontitud y variedad de sus invenciones, y por sus descripciones naturales de las pasiones, especialmente las de carácter alegre y amoroso" (Ibid.). Años después, Hugh Blair en sus Lectures on Rhetoric utilizará el mismo argumento, aunque lo ilustrará con la dramaturgia de Shakespeare.

De todas formas, Hume se debate entre la aceptación de estos principios generales del gusto que, según él, "son uniformes en la naturaleza humana", y el reconocimiento de la existencia de ciertos factores, como "los diferentes temperamentos de los diversos hombres" y "los hábitos y opiniones particulares de nuestra época y de nuestro país", capaces de provocar juicios estéticos muy diferentes (Ibid.: 46). Consciente de que "nos agradan más (...) las escenas y los personajes que nos recuerdan los que encontramos en nuestra propia época y país", no tiene inconveniente en afirmar que "la comedia no es transferible de una época a otra" y que, por ello, "a un francés o a un inglés no les agrada la Andria de Terencio o la Clizia de Maquiavelo" (Ibid.: 48). Sienta así las bases de lo que será la crítica teatral del XIX. Recuérdese que el debate sobre la conveniencia de imitar el teatro antiguo está en el origen del romantictsmo. Por otra parte, en el ensayo titulado Origen y progreso de las artes y las ciencias, Hume proclama la necesjdad de libertad para el desarrollo đel arte. Hume, y antes que él Shaftesbury, observan cómo en Inglaterra, después de la revolución de 1688 , han florecido las antes y las ciencias.

${ }^{\circ}$ Hume declara abiertamente su empirismo al señalar como fundamento de estas reglas la experiencia: "Su fundamento es el mismo que el de todas las ciencias prácticas: la experiencia; $y$ no son más que observaciones generales respecto a lo que universalmente se ha visto que complace en todos los países y en todas las épocas" (lbid.: 29). 


\subsection{Burke y lo sublime}

La primera edición de Philosophical Inquiry into the Origin of the Sublime and Beauliful de Edmund Burke (1729-1797) apareció en Londres en 1757, aunque dos años más tarde se publicaría una segunda con importantes adiciones. En España, Juan de la Dehesa la tradujo en 1807 con el título Indagación filosofica sobre el origen de lo sublime y lo bello. En 1985, Valeriano Bozal reeditaría y prologaría la traducción de Juan de la Dehesa.

La obra incluye un interesante "Discurso preliminar sobre el gusto", en donde Burke intenta resolver el problema de la relatividad del gusto, que ya planteó Hume, haciendo intervenir al juicio, a la razón. Aunque admite la subjetividad del gusto, en cuanto procede de los sentidos de cada individuo, la colaboración del juicio supone un importante freno. De hecho, Burke afirma que "La causa de un gusto irregular es la falta de juicio: y ésta puede nacer de la debilidad natural del entendimiento, $(. .$.$) ; o, como más común-$ mente sucede, de la falta de un ejercicio proporcionado y bien dirigido, que es lo unico que puede fortalecerla y avivarla" (1757: 78)?. Por eso, concluye Burke, "es probable que la regla de la razón y el gusto sea una misma en todas las criaturas" (Ibid.: 63). Al igual que Hume y la mayoría de los teóricos ilustrados, Burke se debate entre el respeto a unas leyes estéticas universales, las del clasicismo, y las nuevas disquisiciones sobre la relatividad del gusto, a menudo contrartestadas con el sentido común.

Pero lo más original del tratado de Burke es la explicación empirista, que puede ser calificada de fisiológica o psicológica, sobre lo sublime y lo bello (Bozal, 1985: 15). El efecto provocado en el lector o en el espectador es el criterio empleado por Burke. Distingue entonces entre placer positivo o amor y deleite penoso. El primero es el característico de la belleza, mientras el segundo lo es de lo sublime: "Las pasiones que pertenecen a la propia conservación, versan sobre la pena y el peligro: son penosas simplemente, cuando nos tocan de cerca: son deleitosas, cuando tenemos una idea de pena y de peligro, sin hallarnos al mismo tiempo en tales circunstancias: no he llamado placer a este deleite, porque versa sobre la pena, $y$ porque es bastante diverso de todas las ideas de placer positivo. Llamo sublime a todo lo que causa este deleite. Las pasiones pertenecientes a la propia conservación son las más fuertes de todas" (1757: 105). Todo lo que pueda suscitar idea de peligro, de asombro, de terror, de oscuridad, de poder, de privación, de vastedad, de infinitud, de dificultad, de magnificencia, de estruendo, etc., es fuente de lo sublime. Llega incluso a describir olores y sabores (hedor y amargura), capaces de excitar en nosotros la idea de sublimidad.

${ }^{\dagger}$ Cito por la edición de Juan de la Dehesa reeditada por Valeriano Bozal en 1985. 
De un modo semejante procede al analizar la belleza. Como indica Menéndez Pelayo, "Nadie puede negarle el mérito de haber pulverizado la vetusta doctrina de la proporción y de la conveniencia" (1883-1891, I: 1055), el mérito de haber rechazado el moralismo y la utilidad, tan importantes para el clasicismo y de tanto peso en la estética de algunos de sus contemporáneos: "En suma, si las partes que se hallan proporcionadas en el cuerpo fuesen siempre bellas; si estuviesen de tal modo colocadas que pudiera resultar placer de compararlas, lo cual rara vez acontece; o si pudieran señalarse algunas proporciones en las plantas o animales, a las cuales estuviera siempre anexa la belleza; o si donde las partes fuesen bien acomodadas para sus fines, siempre fuesen bellas, y no hubiese belleza alguna en aquellas de que no se conociese el uso; podríamos concluir que la belleza consistía en la proporción o utilidad. Pero como todo sucede muy al contrario, podemos estar seguros de que la belleza no depende de ellas, sea el que fuere su origen ${ }^{\text {"* }}$ (1757: 175).

Burke señalará una serie de cualidades sensibles de la belleza; los objetos bellos son pequeños, tersos y lisos, delicados, varían de forma gradual y suave la dirección de sus partes, y poseen colores claros y brillantes, aunque no tan vivos como para deslumbrar. Así lo expresa Burke: "En suma, las cualidades de la belleza, en cuanto son cualidades sensibles, son las siguientes. Primera, el que los cuerpos bellos sean pequeños comparativamente. Segunda, que son tersos. Tercera, que varíe la dirección de sus partes. Quarta, que las partes no sean angulares, sino que se confundan, por decirlo así, o se pierdan las unas en las otras. Quinta, que sean de estructura delicada, sin que en ella aparezca alguna fuerza notable. Sexta, que sus colores sean claros y brillantes; pero que no sean tan vivos que deslumbren. Séptima, que si tienen algún color que deslumbre, esté variado con otros" (Ibid.: 185).

Después intenta justificar por qué son bellas cada una de estas cualidades. La lisura lo es porque resulta agradable al tacto; la dulzura, porque produce relajación; la variación, porque evita la monotonía; la pequeñez, porque no provoca temor; y los colores, porque agradan a la vista. Por tanto, la diferencia entre lo sublime y lo bello es notable". De hecho, mientras "la belleza

" "Al concluir este examen general de la belleza naturalmente ocurre al compararla con la sublimidad, y se ve un contraste notable en esta comparación: pues los objetos sublimes tienen grandes dimensiones, y las de los bellos son pequeñas comparativamente: en los bellos se encuentra lisura y pulidez, en los sublimes aspereza y negligencia: la belleza debe evitar la línea recta, pero apartándose de ella insensiblemente: a lo grande conviene la línea recta en muchos casos, y cuando se desvía de ella, suele separarse mucho: lo bello no ha de ser oscuro, lo grande debe ser opaco u oscuro: lo bello debe ser leve y delicado, lo grande debe ser sólido, y aun pesado. A la 
obra relaxando los sólidos de todo el sistema", la sublimidad se caracteriza por la tensión (Ibid.: 219). El objeto general de la belleza es causar un placer positivo semejante al amor. Burke distingue entre las pasiones pertenecientes a la propia conservación, que son la fuente de lo sublime, y las pasiones que pertenecen a la sociedad y apuntan a la perpetuación de la especie. Estas últimas son la fuente de la belleza, es decir, del placer positivo, del goce amoroso. Por eso, Burke, al describir los efectos fisiológicos que acompañan a la emoción estética recurre a términos amorosos. En definitiva, el canon de belleza descrito por Burke es, como indica Wellek, "social, sexual, menudo, lindo, terso, débil; en suma, típicamente rococ6" (1954-1996, I: 137).

Otro de los méritos que suelen atribuírsele al tratado de Burke es haber rebatido, anticipándose a Lessing, el célebre tópico Ut pictura poesis (Menéndez Pelayo, 1881-1893, l: 1056-1057 y Wellek, 1954-1996, I: 134). Burke utilizará incluso el mismo ejemplo que será explotado más tarde por Lessing en el Laocoonte: Homero no necesita describir la belleza de Helena para comunicarnos la impresión que ésta causó en los ancianos de Troya. Así refuta el carácter imitativo de la poesía: "Por esto podemos conocer que la poesía, tomada en la acepción más general, no puede llamarse arte de imitación con toda propiedad. Es una imitación seguramente, en cuanto describe las costumbres y pasiones humanas que pueden expresarse con palabras, donde animi motus effert interprete lingua. En esto hay una imitación rigurosamente, y toda la poesía meramente dramática es de este género. Pero la poesía descriptiva obra principalmente por sustitución; por medio de los sonidos, los cuales surten el mismo efecto que la realidad, por razón de la costumbre. Ninguna cosa puede llamarse imitación sino en cuanto se parece a otra; y no puede dudarse que las palabras no tienen semejanza alguna con las ideas, en cuyo lugar se sustituyen" (1757: 244).

\subsection{Alexander Gerard: Essay on Taste}

En Essay on Taste (1759), Alexander Gerard (1728-1795) define el buen gusto como un don natural que sólo alcanzará la perfección si se cultiva por medio del arte. El gusto procede de los que Gerard llama 'sentidos interiores', facultades imaginativas que operan sobre un conocimiento previo de los objetos. Por tanto, aportan una percepción más fina y más completa que los

verdad son ideas de muy diversa naturaleza por fundarse la una en la pena, y la otra en el placer; y aunque después no convengan en algo con la naturaleza directa de sus causas, éstas mantienen sin embargo una constante y perpetua distinción, que nunca debe olvidar el que tenga necesidad de mover pasiones" (1757: 193-194). 
'sentidos externos'. Son los siguientes: el sentido de novedad, de sublimidad, de belleza, de imitación, de armonia, de ridículo y de virtud. De la colaboración entre ellos nace el gusto, que pretende así alcanzar un carácter general. De todas formas, Gerard reconoce las dificultades para que estos sentidos internos produzcan juicios universales y salgan fuera del estrecho ámbito del gusto individual. Por eso, al final ha de recurrir al consabido peso de la tradición como único criterio váliđo de valoración (Bayer, 1961: 262-264).

\subsection{Edward Young: hacia el carácter sobrenatural del genio}

En el 'Prefacio' a su oda Ocean (1728) y en el 'Prefacio' a Imperiam Pelagi, Young ya había distinguido, como otros contemporáneos suyos (Pope, Addison, Hutchenson, etc.), entre el genio natural de la Antigujedad y el genio que procede del estudio de las reglas y los modelos. Pues bien, en su célebre Conjectures on Original Composition (1759), Young insiste en esta distinción (original geniu.s / imitative genius): "La de la naturaleza, la de los autores. Llamaré a la primera original y guardaré el término imitación para la segunda". Y añade: "Cuanto menos copiemos a los célebres antiguos, tanto más nos pareceremos a ellos" (apud Bayer, 1961: 268). Obsérvese cómo Young se resiste ya a aceptar el término imitación para la poesía original. De hecho, apuesta por el poder creativo (creative power): "En el reino de las hadas el genio puede vagabundear libremente; allí tiene poder creador y puede reinar a su albedrío sobre su propio imperio de quimeras" (apud Abrams, 1953: 487). Además, ya no define el genio sólo como un don natural o innato sino que le atribuye un carácter misterioso y divino, tal como harán los escritores románticos: "el genio siempre se ha supuesto que tiene algo de divino. Nemo umquam vir magnus fuit, sine aliquo afflatu divino" y "Hay algo en la poesía que está más allá đe la razón prosaica; bay misterios en ella que no han de ser explicados sino admirados" (apud Abrams, ibid.: 352). La obra deja de ser entonces un artefacto, una mechanical manufacture para convertirse en un objeto natural: "Un original puede decirse que es de naturaleza vegetal: brota espontáneamente de la raíz vital del genio; crece, no es hecho. Las imitaciones son a menudo una suerte de labor o arte mecánico a partir de materiales preexistentes que no son propios" (Ibid.. 352-352).

Este pasaje sería luego aprovechado por Coleridge para distinguir entre fabricación mecánica y desarrollo orgánico, entre la reorganización de materiales ya existentes propia de Beaumont y Fletcher (poetas artífices), y el surgimiento de una forma verdaderamente original en Shakespeare (Ibid.: 353).

$\mathrm{La}$ influencia de las Conjectures fue mucho mayor en Alemania que en lnglaterra. Herder, Goethe o Kant manejarán también los conceptos de genio natural, crecimiento orgánico, inspiración, etc. (lbid.: 353-356). 


\subsection{Adam Smith: la estética de un economista}

Como economista que es, a Adam Smith (1723-1790) le van a interesar especialmente dos fenómenos: la costumbre y la utilidad. Llama la atención, por ejemplo, sobre la importancia de la costumbre para el juicio estético: "Casi no hay una sola forma exterior, con el grado de belleza que fuere, que pueda gustar si es contraria a la costumbre y a lo que nuestros ojos están habituados a ver; a la inversa no hay nada tan deforme que no pueda gustar si la costumbre lo autoriza y nos habitúa a reconocerla en cada individuo de una misma especie" (apud Bayer, 1961: 239). El gusto, por tanto, serå una cuestión social. El crítico ha de operar con dos criterios. Primero debe comparar la obra con la idea de perfección estética que él mismo se haya formado gracias a la costumbre y al estudio. Después ha de comparar la obra con otras similares y establecer el lugar que ocupa entre ellas. De esta manera tan simple, propia de una mente economista, resuelve Adam Smith las habituales fricciones entre la relatividad del gusto y la norma del gusto.

La simpatía es otro de los conceptos críticos que utiliza. La define como contagio afectivo que exige previamente el reconocimiento, pero un reconocimiento desinteresado. No hay simpatía auténtica mientras no conozcamos las causas de la pena o la alegría del otro y éstas además no nos afecten directamente. Esta situación se produce sobre todo, dice Adam Smith, cuando contemplamos las obras artísticas. La problemática del desinterés vuelve a reaparecer curiosamente al intentar definir la utilidad del arte. El arte para ser útil ha de contener simplemente la idea de utilidad, pero no ha de servir para nada.

\subsection{Alison: la simpatía como enajenación}

Archibald Alison, en Essay on the Nature and Principles of Taste (1790), desarrolla las ideas de Adam Smith sobre la simpatía, aunque la emoción estética que provoca en nosotros adquiere con él un sesgo incontrolado. Se convierte en una especie de estado de inconsciencia que potencia al máximo la captación de lo sublime y de lo bello. Según Alison, "en un estado inerme de ensueño, mientras nuestras concepciones nos arrastran en vez de conducirlas nosotros, es cuando se sienten las más profundas emociones de lo bello o lo sublime, cuando nuestros corazones se impregnan de sentimientos que la palabra es demasiado pobre para expresar, y cuando en lo hondo del silencio y del pasmo rendimos al hechizo que nos domina la muestra más halagadora de nuestro aplauso" (apud Wellek, 1954-1996, I: 135). La enajenación que caracterizará al vate romántico se traslada ya con Alison, en pleno periodo ilustrado, al lector o espectador de las obras de arte. 


\subsection{Reynolds o la imitación idealizadora}

Los Discourses de Sir Joshua Reynolds (1723-1729) estuvieron destinados a los estudiantes y miembros de la Royal Academy, para quien Reynolds los compuso entre 1769 y $1790^{\circ}$. Contienen teorías típicamente clasicistas como la importancia de los modelos (la Antigüedad grecolatina, el arte renacentista italiano) o el acatamiento de las reglas. Ahora bien, Reynolds defiende algunos principios que se salen del estrecho patrón clasicista. Y esto puede apreciarse "in the emphasis Reynolds places on association as a factor in aesthetic response, in his insistence that art must appeal to the imagination, and in his willingness to accept considerable individualism in the matter of style" (Wark, 1988: XXV). Pero quizís sea su concepto de imitación el más interesante. Reynolds apuesta por una imitación idealizadora de la naturaleza, una imitación que perfeccione el original prescindiendo de particularidades y localismos para representar lo típico, lo característico. A veces esta imitación idealizadora tiene un sesgo platónico, ya que Reynolds la define como la "imagen de perfecta belleza" que el artista tiene en su mente. Pero incluso puede estar referida a un mundo que sólo existe en la imaginación. Y esto es lo más original de la teoría de Reynolds, lo que nos hace vislumbrar el romanticismo: "El objeto y la finalidad de todas las artes es suplir la natural imperfección de las cosas y, con frecuencia, contentar a la mente al hacer realidad y dar cuerpo a lo que nunca existió más que en la imaginación" (apud Wellek, 1954-1996, I: 136).

\section{La crítica literaria}

\subsection{La teoría de la pasión de John Dennis}

Como la mayoría de los neoclásicos, John Dennis creía en la validez universal de las reglas, estaba convencido de que los grandes autores de la Antigüedad escribieron no para sus compatriotas, sino "para conciudadanos del Universo, para todos los países y para todas las edades". Expresaban así "la Regla y el Orden, y la Armonía, que encontramos en la Creación visible" (apud Abrams, 1953: 38). Sin embargo, su reelaboración del concepto longiniano de lo sublime, su teoría de la pasión, le colocan en el origen de algunas ideas románticas.

Dennis es el primer teórico inglés que evidencia el influjo de las teorías de Longino sobre lo sublime (Abrams, ibid.: 138). En The Grounds of Criticism in Poetry (1704) ya define la poesía como "un arte, por el cual el poeta excita la pasión" (lbid.). El carácter mimético de la poesía cede ante su

\footnotetext{
'Puede consultarse la edición de Robert R. Wark, publicada por la Universidad de Yale en 1988.
} 
carácter emotivo. La poesía, dice, "es poesía porque es más apasionada y sensual que la prosa". La pasión "es el distintivo de su verdadera naturaleza y carácter" (lbid.: 139). De esta forma, Dennis realiza una formulación particular de lo sublime longiniano. Si para Longino la pasión era sólo una de las variadas fuentes de lo sublime, Dennis la convierte en la única fuente de toda poesía. Y añade la ya consabida teoría de que el lenguaje propio de la pasión es el lenguaje figurado. Además, cuando relata el origen histórico de la poesía, lo sitúa en la emoción religiosa: "La religión primeramente produjo (la poesía) como una causa produce su efecto... Pues las maravillas de la religión naturalmente los impulsaron a grandes pasiones, $y$ las grandes pasiones naturalmente los impulsaron a la armonía y el lenguaje figurado" (apud Abrams, ibid.: 145). Se anticipa así a quienes exaltarian la literatura primitiva por ser aquella en la que la pasión se expresó de forma mâs directa.

\subsection{Alexander Pope o el crítico artista}

El Essay on Criticism (1711) de Alexander Pope (1688-1744) ha sido considerado un "verdadero código del clasicismo anglo-francés" (Menéndez. Pelayo, 1881-1893, II: 344). Entre sus fuentes, figuran las autoridades grecolatinas -Aristóteles, Horacio, Quintiliano y Longino-, tal como las leyeron los humanistas italianos del siglo XVI y los críticos franceses, en especial Boileau (Winsatt, 1967: XX11). En estas autoridades se apoyan los preceptos universales de la belleza. Siguiendo a Boileau, Pope conciliará los principios que proceden de la naturaleza o de la razón y los que proceden de la tradición, convencido de que ambos se basan en verdades objetivas y universales. Para ello se sirve de dos conceptos propios de la estética ilustrada: el taste (gusto) y el good sense (buen sentido). Define el primero como una "grace beyond the reach of art" (una gracia fuera del alcance del arte), mientras que el good sense ha de ser cultivado mediante el estudio y las reglas (Ibid.: XX111). Pues bien, ambos deben estar presentes tanto en el artista como en el crítico. El crítico no sólo ha de conocer los preceptos sino que ha de poseer la sensibilidad suficiente como para penetrar en el interior de la obra y de su autor. Y esto es quizás lo más significativo y lo más original de la teoría de Pope (Menéndez Pelayo, 1881-1893, 11: 344). Anticipa así las reflexiones de la crítica impresionista en el XIX sobre el crítico-artista.

Este Essay on Criticism tuvo una acogida desigual en su época. Se granjeó las iras del veterano John Dennis, molesto al parecer por la crítica favorable que Addison hizo sobre la obra en el Spectator. Dennis escribió contra el ensayo de Pope un opúsculo titulado Reflexiones críticas y satíricas sobre tuna rapsodia reciente, situlada Un ensayo sobre la crítica ${ }^{\text {tD }}$.

${ }^{10}$ Samuel Johnson relata las críticas de Dennis en su «Vida de Pope». Pueden leerse ел la edición de Bernd Dietz de Vidas de los poetas ingleses (1988: 302-306). 
Pope es también autor de una edición de las obras de Shakespeare (1725), en cuyo 'Prefacio' podemos encontrar algunas ideas que después repetirá la crítica romántica, como el concepto de originalidad o el de inspiración. Shakespeare es para él el poeta de la naturaleza, indiferente por completo a modelos y normas: "Si jamás un autor mereció el nombre de original, fue Shakespeare. Ni el propio Homero bebió su arte tan directamente en las fuentes de la naturaleza; ésta vino a él sin el menor tinte de saber o el menor rasgo de los modelos anteriores a él. La poesía de Shakespeare fue inspiración, en verdad; $y$ no es tan exacto decir que él habla siguiéndola como ella habla por intermedio de él" (apud Abrams, 1953: 334).

Insistirá sobre esta idea del genio natural en su 'Prefacio' a la traducción que realizó de La llíada en 1715. Allí dice que los grandes genios se parecen a la naturaleza, que La líada es como "un paraíșo salvaje" y que "como en los jardines más regulares, el arte sólo puede reducir a más regularidad las bellezas de la naturaleza" (apud Abrams, ibid.: 334-335)". Pero lo más curioso es que estos artistas espontáneos y libres, que no atienden a la preceptiva, tampoco pueden ser enjuiciados por ella. Según Pope, "Juzgar por consiguiente a Shakespeare de acuerdo con las normas de Aristóteles es como juzgar por las leyes de un país a un hombre que actuabalbajo las leyes de otro" (apud Abrams, ibid.: 387). Con este juicio sobre Shakespeare, Pope pone en entredicho la universalidad y la eternidad de esas normas del good sense, avaladas por la tradición, que con tanto empeño había sostenido en su Essay on Criticism. Pero a lo que no renuncia es a la imitación de la naturaleza. Y gracias a ella logrará salvar el precepto de la imitación de los antiguos, ya que "Copiar la naturaleza -dice- es copiarlos a ellos" (apud Bayer, 1961:267).

\subsection{Lord Kames: la aristocracia del gusto}

Henry Home of Kames (1696-1782), en sus Elements of Criticism (1762), se muestra totalmente convencido de la existencia de una norma del gusto, común a todas los lugares y a todos lo tiempos. La formulación que realiza de esta norma es neoclásicn: "Sobre una convicción común a la especie se erige un estándar del gusto que se aplica, sin vacilación alguna, al gusto de cada individuo. Este estándar, al afirmar qué acciones son rectas y cuáles falsas, cuáles son apropiadas y cuáles impropias, ha permitido a los moralistas establecer reglas para nuestra conducta de las que nadie debe apartarse. Tenemos el mismo estándar para poder decir con seguridad en todas las be-

"Este Prefacio ha sido incluido por Francisco Lafarga en la antología bilingüe $E l$ discurso sobre la traducción en la historia (1996: 198-210). 
llas artes qué es hermoso y qué no lo es, qué es elevado y qué mezquino, proporcionado o desproporcionado: y aquí, de modo parecido a como lo hacemos en la moral, condenamos justamente todo aquel gusto que se separa de lo que ha sido reconocido por el estándar común" (apud Bayer, ibid.: 266).

Pero Lord Kames exhibe además una concepción muy aristocrática del gusto, excluyendo de su posesión a varios tipos humanos: "Los que dependen del trabajo corporal para su sustento carecen totalmente de gusto, $o$, al menos, del gusto que puede servirnos en las bellas artes. Esta consideración elimina a la mayoría de los seres humanos; de la parte restante hay muchos que por su gusto corrompido están descalificados para emitir su voto. Así pues, hemos de limitar el buen sentido de la humanidad a los pocos que no caen dentro de estas excepciones" (apud Wellek, 1954-1996, I: 131).

Ahora bien, Kames es muy permisivo con las reglas clasicistas más emblemáticas: las famosas unidades de acción, tiempo y lugar. Sólo considera obligatoria la unidad de acción. A las otras les concede poca importancia, como simples auxiliares. Sin embargo, desaprueba la tragicomedia, por la mezcla de pasiones de distinta naturaleza, aunque reconoce con una flexibilidad sorprendente que "las composiciones literarias se funden entre sí igual que los colores: $\mathbf{w}$ los tonos fuertes se les distingue fácilmente, pero se prestan a tantas variedades y a formas tan diferentes que nunca puede decirse dónde empieza una especie y acaba la otra" (apud Wellek, ibid.: 139).

Estudiará además, como ya hiciera Burke, los conceptos de belleza y sublimidad. La belleza es una cualidad de aquellos objetos que podemos percibir sobre todo a través de la vista. Es, por tanto, algo visual, relativo al color, tamaño, figura o movimiento de los objetos, que suele suscitar en nosotros dulzura y alegría. Hay, además, dos tipos de belleza: la intrínseca y la relativa. La intrínseca se da en los objetos por sí mismos y depende de la regularidad, el orden, la proporción y la simplicidad. La belleza relativa se basa en la relación de varios objetos. Aquí introduce Kames la cuestión de la utilidad. Un objeto será bello si es conveniente, si cumple a la perfecciốn la finalidad para la que ha sido creado. En cuanto a lo sublime, más que una cualidad de los objetos, es una reacción emotiva del sujeto que percibe. La elevación y la grandeza son sus dos notas características (Bayer, 1961: 241-244).

Como otros intelectuales de la época, Kames va a rebatir también el carácter imitativo de algunas artes. Para él sólo poseen esta condición la pintura y la escultura. La arquitectura, la música o la poesía producen en realidad no copias de la naturaleza sino originales. El lenguaje no imita la realidad: la sustituye (Ibid.: 251).

\subsection{Samuel Johnson, el crítico}

Samuel Johnson (1709-1784) es considerado como la "figura indiscutiblemente dominante de la escena cultural del Siglo de las Luces" (Dietz, 
1988: 9). Una de sus primeras grandes empresas fue la publicación de un Diccionario de la lengua inglesa (1746), que se convertiria en el primer diccionario histórico del inglés. Le siguen los ensayos periódicos del Rambler ${ }^{12}$ (1758-1760), el Rasselas (1759), la edición de Shakespeare (1765) y la que será su obra más célebre: Lives of the Poets (1779-1781), ya en plena madurez.". Se ha hablado mucho de "Ia rapidez increíble con que escribía sus obras", siempre "bajo la presión de un contrato y por motivaciones económicas inmediatas", lo que le aleja bastante de la imagen contemporánea del crítico profesional (Dietz, 1988: 15). Con todo, Johnson creía que una sólida preparación, no sólo en letras sino también en derecho o en las ciencias experimentales, era requisito imprescindible de todo buen crítico (Ibid.: 13). No en vano la función de la crítica había de ser la formulación de preceptos o leyes generales, preocupación, como sabemos, fundamental en los teóricos ilustrados. Hay, en efecto, muchos principios estéticos de Johnson que responden claramente a la ortodoxia neoclásica. Sin embargo, otros muchos apuntan ya hacia el romanticismo. No es ésta, por supuesto, una característica peculiar de Johnson. En otros intelectuales de la época hemos podido constatar los primeros atisbos de teorias que alcanzarían luego gran notoriedad en la estética romántica. Pero el contundente rechazo de Johnson a las unidades dramáticas, o su condena de la imitación de los antiguos, unido a la celebridad personal que alcanzó en su época, le han convertido, a juicio de algunos, en "el eslabón entre el neoclasicismo y la crítica moderna" (lbid.: 14).

La íntima conexión del arte con la verdad, y por tanto el realismo, es un precepto de índole clasicista, que Johnson acató como eje principal de sus teorías estéticas. EI arte es para él un fragmento de vida. Así lo indicó en el 'Prefacio' a su edición de Shakespeare: "Ésta es, pues, la alabanza que merece Shakespeare: que su teatro es espejo de la vida" (apud Wellek, 19541996, I: 96) ${ }^{14}$. Y se pueden hallar en todas sus obras declaraciones similares.

12 Sobre el Rambler y sobre el Diccionario escribió en 1968 William K. Wimsatt Jr. un interesante ensayo titulado Plilosophic Words. A Study of Style and Meaning in the Rambler and Dictionary of Samuel Johnson.

"Hay edición española de esta obra, publicađa por Bernd Dietz en 1988.

"Y la cita continúa asi: "que quien ha aturdido su imaginacjón, siguiendo los fantasmas que otros escritores han hecho surgir ante él, puede curarse aquí de sus éxtasis delirantes, leyendo sentimientos humanos en la lengua de los hombres, escenas con las que un ermitaño puede medir los casos mundanales y un confesor predecir el desarrollo de las pasiones... Shakespeare no tiene héroes; llenan sus escenas hombres que obran y hablan como el lector piensa que habría obrado o hablado en análogo ocasión... Los diálogos de este autor suelen estar tan determinados por la situación que los provoca, y desarrollados de modo tan natural y sencillo, que, lejos de merecer el título de ficticios, parecen haber sido entresacados por diligente selección de las conversaciones cotidianas y los sucesos de todos los días". 
Por ejemplo, en Lives of the Poets dice que la literatura es "fiel representación de lo realmente existente y de acciones realmente realizadas", y que "la legítima finalidad de la ficción es comunicar la verdad" (Ibid.: 98). Y en Rasselas señala que los novelistas han de ser "fieles imitadores de las costumbres humanas" (Ibid.). Hasta tal extremo lleva a veces Johnson este precepto que llega a criticar el Lycidas de Milton o la poesía erótica de Cowley porque no está basada en una experiencia personal verdadera, y por eso amonesta duramente a quien "ensalza la belleza que nunca ha visto, se lamenta de los celos que nunca ha sentido" (lbid.: 99). Por eso, también rechazará la mitologia antigua, que es falsa, o el género pastoril. Una de sus objeciones primordiales al Lycidas miltoniano y a otros autores que cultivaron la pastoral es que "nunca salieron al campo ni tenían ganado que apacentar" (Ibid:: 100). Por razones similares, despreció los libros de caballerías e incluso las novelas, aunque Evelina de Fanny Burney se granjeó su simpatía por la observación de la vida y las costumbres (Ibid.: 101). Tampoco le agradó la poesía metafísica (Donne, Cowley, Milton) que para él era sinónimo de "especulación irrefrenada' y excesos imaginativos (Dietz, 1988: 31 ).

La moralidad es otro de los principios fundamentales de la estética de Johnson, principio de evidente naturaleza clasicista. La enseñanza moral es para él una prioridad, por delante incluso del realismo. Prefiere la expresión de la virtud aun contraviniendo la normas de lo verosímil. La crítica que hace a Shakespeare, autor por quien siente un admiración especial, es justamente una crítica moral: "Sacrifica la virtud a la conveniencia y cuida mucho más de agradar que de instruir, hasta el punto de que parece escribir sin propósito moral de ninguna clase... No distribuye en justicia el bien ni el mal, ni cuida en todo momento de mostrar al virtuoso desaprobando al malvado; lleva a sus personajes indiferentemente por entre lo bueno y lo malo, y al final se despide de ellos sin preocuparse de más, y deja que su ejemplo obre a la aventura. Es ésta una falta que no puede disculparse con la barbarie de su época, porque el deber sempiterno del escritor es hacer mejor el mundo y la justicia es virtud independiente de tiempo o lugar" (apud Wellek, 1954-1996, I: 102-103).

La necesidad de hallar conceptos universales, válidos en todo tiempo y en todo lugar, atenaza, como hemos visto, a los teóricos neoclásicos. Pues bien, Johnson, convencido de que "la naturaleza humana es siempre la misma" (Ibid.: 104), recomendará a los poetas la representación de lo típico y condenará lo particular, lo localista o lo que es simplemente una moda transitoria. Por esta causa censura la descripción que Shakespeare hace en el King Lear de los acantilados de Dover. Es mús, para Johnson el consenso general, la tradición son valores muy importantes: "Lo que la humanidad ha poseído largo tiempo, Jo ha podido examinar y comparar con frecuencia; y si persiste en conceder valor a esta posesión es porque las repetidas comparaciones han confirmado la opinión favorable" (Ibid.: 103). 
Ahora bien, Johnson va a rechazar la imitación de los antiguos. En el Rambler proclama: "Nadie se ha engrandecido imitando" (Ibid.). De igual forma, en el dilema ingenium / ars parece decantarse por el genio antes que por las reglas del arte, aunque son estas reglas las que la crítica debe formular y observar escrupulosamente. No obstante, para no incurrir en ninguna contradicción, Johnson afirma que "las prescripciones accidentales de la autoridad, cuando el tiempo les ha granjeado veneración, suelen confundirse con las leyes de la naturaleza" (Ibid.: 107). No es éste el caso de las famosas tres unidades dramáticas, que Johnson condena sin ningún miramiento a excepción de la unidad de acción. El argumento utilizado es la ilusión dramática: si el espectador, cuando va al teatro, es consciente de que lo representado en escena es ficticio, ¿qué importancia tiene que la ficción se desarrolle en un sólo lugar o en varios, en el tiempo real de la representación o épocas dispares? ${ }^{13}$ En cuanto a la tragicomedia, Johnson la acepta con argumentos realistas: "Siendo no sólo comunísima, sino perpetua en nuestro mundo la conjunción de incidentes importantes y humildes, bien puede permitírsele tener cabida en el teatro, cuya única aspiración es ser espejo de la vida" (Ibid.: 108). Llega incluso a afirmar que en las obras de Shakespeare no se pueden distinguir géneros, que no son comedias ni tragedias en sentido estricto, porque participan "de lo bueno y de lo malo, de la alegria y de la tristeza, mezclado todo en proporciones de infinita variedad" (Ibid.: 109). Es evidente que "Shakespeare era para él el primer poeta inglés de todos los tiempos" (Dietz, 1988: 28), muy superior a los dramaturgos franceses. De Corneille, por ejemplo, decía que "es, con respecto a Shakespeare, como un seto recortado respecto a una selva" (apud Wellek, 1954-1996, I: 122).

Desde el punto de vista lingüístico y formal, Johnson es, sin embargo, muy conservador. Mantiene la idea clásica de la propiedad y la conveniencia (decorum) del lenguaje, y se muestra poco complaciente con las innovaciones métricas: "el mayor deleite de la poesía brota del metro conocido de los versos y de la estructura uniforme de las estrofas" (apud Wellek, ibid.: 113).

11 "La objeción basada en la imposibilidad de pasar la primera hora en Alejandría y la siguiente en Roma, supone que al empezar la obra el espectador se imagina estar realmente en Alejandría y cree que su camino hasta el teatro ha sido un viaje a Egipto, y que vive en los días de Antonio y Cleopatra. Quien es capaz de imaginarse esto, sin duda que podrá imaginarse mucho más... La verdad es que los espectadores estún sjempre en sus sentidos cabales y saben, desde el acto primero al último, que el escenario no es más que un escenario y que los actores no son más que actores... ¿Qué hay de absurdo en permitir que represente Atenas, y después Sicilia, un lugar que en todo momento se sabia que no era Sicilia ni Atenas, sino un teatro moderno" (apud Wellek, ibid.: 108). 
Manejará también los conceptos típicos de la época: gusto, sentido común, imaginación, sublime, etc. La influencia de Edmund Burke se percibe cuando distingue entre lo bello y lo sublime a partir de la oposición de lo grandioso y lo pequeño. Afirma, además, la relatividad del gusto, pero enseguida la compensa con el sentido común y la tradición. Se inclina por el genio, por las dotes innatas, y de la imaginación tiene una concepción plenamente clasicista: facultad de reproducir visualmente cosas ausentes.

Pero el interés por la historia, que comenzaba a acuciar a los intelectuales ilustrados y que luego sería una de las notas distintivas del romanticismo, estará presente en Johnson, sobre todo en Lives of the Poets, que ofrecen, según Wellek, "un esquema implícito de la historia de la poesía inglesa en el siglo anterior" (Ibid.: 124). En esta obra, los juicios políticos a menudo condicionan los estéticos, como en el caso de la biografía de Milton. El monárquico Johnson no podía evitar un profundo desacuerdo con los ideales republicanos de Milton (Dietz, 1988: 34). Entre los logros de Lives of the Poets, la critica suele mencionar la capacidad que tiene Johnson para "establecer vínculos eficaces entre los elementos biográficos y la realidad de la obra" (Ibid: $37)$.

\subsection{William Blake: una peculiar interpretación de Milton}

En "Las bođas del cielo y el infierno", texto incluido en la edición de Geoffrey Keynes de la Poetry and Prose of William Blake (1939), hay una curiosa interpretación del Paradise Lost miltoniano, que Abrams ha llegado a denominar 'protofreudiana' (1953: 443) ${ }^{\text {th }}$. Según Blake, la derrota de Satán no es sino la derrota de las pasiones y la imaginación del ser humano a manos de la razón (Jesucristo): "Los que constriñen el deseo lo hacen así porque es lo bastante débil para ser constreñido; y el que constriñe, es decir, la razón, usurpa su lugar y gobierna al que carece de voluntad...". La historia de esto está escrita en El Paraíso Perdido de Milton y el gobernante o la razón es llamada el Mesías (apud Abrams, ibid.).

Pero lo más interesante es la opinión de Blake sobre la posición de Milton que, según él, por el entusiasmo con el que perfila las acciones de Satán, se identifica aunque de forma inconsciente con la imaginación y la libertad simbolizadas en el héroe demoníaco. Blake cree descubrir un sentido oculto en el texto de Milton, una intención inconsciente. Familiarizado con la tradición

16 $\mathrm{El}$ mismo calificativo le merece una obra del XIX: De poeticae vi medica (1844) de John Keble (Ibìd.: 262). Wellek calificará también de 'pre-psicoastalista' a Eneas Sweetland Dallas (1828-1879) por Poetics (1852) y The Gay Science (1866) (1954-1996, IV: 193). 
de los intérpretes de la Biblia, con la cábala, Swedenborg y otros representantes del ocultismo, pone sus conocimientos al servicio de una interpretación que contradice el significado manifiesto de la obra y apuesta por los valores inconscientes. Se anticipa así al tipo de crítica que mucho tiempo después, ya en el siglo XX, aprovecharía las conquistas del psicoanálisis freudiano y las aplicaría a los textos literarios. Y lo más curioso es que el texto de Blake está fechado en torno a 1793.

Hay además otro fragmento en el que Blake vuelve a tocar el tema del inconsciente, ahora no aplicado a la crítica literaria sino a la creación. En 1803, en una carta a Thomas Butt, explicaba así la escritura de su Milton: "He escrito este poema, al dictado inmediato, doce y a veces veinte o treinta líneas a un tiempo, sin premeditación y hasta contra mi voluntad; el tiempo que tomó el escribirlo fue así inexistente, y un inmenso poema existente, que parece ser la labor de una larga vida, producido todo sin labor ni estudio (apud Abrams, ibid.: 381 ). Por este texto, Abrams ha llegado a calificar a Blake como "el reivindicador más extremo del automatismo poético" (Ibid.),

En cuanto a la imaginación, con Blake alcanza cotas insospechadas. Es la cualidad por excelencia del verdadero poeta y obtiene un rango divino: "sólo una facultad hace al poeta: la imaginación, la visión divina" (apud Wellek, 1954-1996, I: 133). A través de ella podrá penetrar en los misterios del universo. El simbolismo, las teorías místicas sobre el conocimiento y la interpretación tienen en Blake a un sen̄ero representante, que se opuso además con dureza a las pretensiones universalistas de la preceptiva clásica. Cuando anota los Discourses de Reynolds puntualiza: "Generalizar es de necios. Particularizar es el único distintivo del mérito" (Ibid.: 137).

\subsection{Los géneros literarios}

Algunos tratados de la época se ocuparon de forma monográfica de cuestiones relacionadas con los géneros literarios. En el ámbito teatral, por ejemplo, el creciente desprecio de las unidades impulsó a los críticos a concentrarse en los caracteres. Surgirán así algunos estudios sobre los personajes dramáticos, y en particular sobre los personajes shakespeareanos. Joseph Warton publicó en el Adventurer (1753-1754) interesantes reflexiones sobre Ariel, Caliban y el rey Lear, inaugurando un tipo de crítica que él mismo llama 'psicológica' (Ibid.: 140). En el Mirror (1780), Henry Mackenzie incluyó ensayos sobre Hamlet, "precursores de la comprensiva interpretación que Goethe daría a las flaquezas de este personaje" (Ibid.). Las disquisiciones morales ocupan los trabajos de William Richardson sobre Shakespeare: Essays on Shakespeare's Dramatic Characters of Richard the Third, King Lear, and Timon of Athens (1786) y Essays on Shakespeare's Dramatic Character of Sir John Flastaff, and on his Imitation of Female Characters 
(1789). Pero el más elogiado de todos quizás sea el Essay on the Dramatic Character of Jolin Falstaff (1777) de Maurice Morgan, que pretende acabar con los calificativos de cobarde y fanfarrón lanzados contra Falstaff. Morgan utiliza el término simpatía para explicar la actividad del crítico, que debe "penetrar en el espiritu interno de las composiciones" del escritor (apud Wellek, ibid.: 141).

De los efectos de la tragedia, el terror y la piedad, ya hemos hablado a propósito de Hume y de Burke. Pero la comedia no ha sido objeto de ninguna reflexión hasta ahora. James Beattie en sus Essays on Poetry and Music (1776) le dedicará un espacio considerable. Mientras que la simpatía domina en la tragedia y tiene la capacidad de penetrar "profundamente en los caracteres que concibe, de convertirse, por unos momentos, en la misma persona que presenta, y de sentir sus sentimientos todos" (apud Wellek, ibid.: 134 135), la visión cómica carece de simpatía y de imaginación. Es, según Beattie, una visión fría, distanciada, intelectual.

Las teorías épicas van a girar en este momento en torno a tres cuestiones fundamentales: la interpretación de Homero como un poeta primitivo, el descubrimiento de Ossian y la defensa de la épica italiana (Ariosto y Tasso) ${ }^{17} \mathrm{y}$ de su discípulo inglés: Spenser. La consideración de Homero no como un clásico sino como un poeta primitivo se debe a la obra de Thomas Blackwell, Enquiry into the Life and Writings of Homer (1735). En cuanto a Ossian, habría que destacar el ensayo de Hugh Blair Critical Dissertation on the Poems of Ossian (1763), sobre el que volveremos después. La épica de Spenser, y en concreto Faerie Queene, encontró un entusiasta defensor en Thomas Warton y sus Observations on the Faerie Queene (1754). Warton, al igual que Pope hiciera con Shakespeare, dirá que ni Ariosto ni Spenser pueden ser juzgados por unos preceptos, los clasicistas, que ellos no tenian en cuenta a la hora de escribir sus obras. No rechaza Warton absolutamente estos preceptos, pero inclina la balanza del lado de la imaginación: "las facultades de la imaginación creadora nos deleitan porque no están asistidas ni restringidas por las del juicio deliberado... Aunque la Faerie Queene no nos satisfaga como criticos, nos arrebata como lectores" (apud Wellek, ibid.: 145). Richard Hurd, sin embargo, no reconoce ningún atentado contra las reglas en la obra de Spenser. En Lettres on Chivalry and Romance (1762) elogiará sin reparos la épica de Spenser y la de Tasso, mostrando incluso aprecio por los libros de caballerías y los cuentos de hadas. Los magos y brujas medievales le agradan más que las deidades grecolatinas porque, de acuerdo con las disquisiones

${ }^{17}$ Ya existia un interesante precedente en el siglo XVI. Me refieto a la Apologie of Poetrie que Sir John Harington colocó al frente de su traducción del Orlando furioso (Wellek, ibid: 144). 
sobre lo sublime propias de la época, son más "sublimes, más terribles, mís inquietantes que los de las fábulas clásicas" (apud Wellek, ibid.).

La novela, género no contemplado en la preceptiva aristotélica, crea serios problemas a los tratadistas, que con frecuencia expresan su desprecio hacia ella. Enseguida comentaremos el caso de Hugh Blair. Pero Hurd, por ejemplo, las llama "poemas precipitados, imperfectos y abortados" (Ibid.: 146). Al final del siglo el interés por este género se incrementa con obras como The Progress of Romance (1785) de Clara Reeve o A View of the Commencement and Progress of Romance (1790) de John Moore. Ambos pretenden realizar la historia del género describiendo sus antecedentes medievales. Clara Reeve distingue además entre narración fantástica o romance y narración realista o novel. Esta última es una "pintura de la vida y de las costumbres tomada de la realidad", que sí acata el principio de verosimilitud aristotélico (apud Álvarez Barrientos, 1991: 28). Esta distinción se utilizará después con mucha frecuencia y está en el origen de la novela fantástica del XIX.

La lírica sufrirá una gran transformación gracias al énfasis en el sentimiento y en la pasión, que puede constatarse en algunos tratados de la época. Este énfasis traerá consigo un renovado interés por el lenguaje figurado, que se asocia con lo sublime y que se supone más cercano al corazón y, en consecuencia, a la poesía del hombre puro, natural, primitivo. Arranca de aquí la creencia romántica en que la expresión por excelencia del hombre primitivo fue la poética. Y se dan los primeros pasos para la valoración positiva de la lírica medieval. Lowth, en De sacra poesi Hebraeorum (1753), estudiará las figuras retóricas y las ilustrará con ejemplos tomados de la Biblia, sentando las bases para la distinción de la prosa como el lenguaje de la razón y la poesía como el lenguaje de la emoción. Además, en Lowth se percibe ya claramente la primacía de la lírica sobre los otros géneros: "Desde que el intelecto humano se deleita naturalmente con toda especie de imitación, aquella especie en particular, que exhibe su propia imagen, que despliega y pinta aquellos impulsos, inflexiones, perturbaciones y secretas emociones que ella percibe y conoce en sí misma, puede difícilmente dejar de asombrar y deleitar por sobre toda otra" (apud Abrams, 1953: 143).

Daniel Webb define las figuras como el lenguaje de la pasión y analiza el estilo metafórico de Shakespeare en Observations on the Correspondance between Poetry and Music (1769) y Remarks on the Beauties of Poetry (1762). Y Sir William Jones, con el Essay on the Arts, commonly called Imitative (1772) afirma la primacía de la lírica sobre la dramática y la épica. De hecho, rechazará toda imitación, porque para él la poesía es fundamentalmente lírica: "Las partes más bellas de la poesía, la pintura y la música son expresión de pasiones y actúan en nuestro espiritu por simpatía. Las partes inferiores describen objetos naturales y nos afectan, principalmente, por sustitución" (apud Wellek, 1954-1996, I: 147). 


\subsection{Un creciente interés por la historia literaria}

El desacato a la preceptiva clísica protagonizado por algunos escritores tan significativos y tan exitosos con Shakespeare provocó en la crítica del XVIII un replanteamiento de la historia literaria, que dejo de ser un todo regido por la autoridad de la Antigüedad grecolatina para atender a las características peculiares de cada nación. Así lo indicó ya Alexander Pope, al enjuiciar la dramaturgia shakespeareana. Y no sería el único. Por tanto, se le comienza a dar mucho importancia al ambiente, a las condiciones en las que surge la poesia. En Essay on Pope (1756-1782) Joseph Warton sostiene que no es posible "saborear por completo, ni comprender perfectamente a un autor, sobre todo a los antiguos, si no tenemos constantemente ante los ojos su ambiente, su país, su ếpoca" (apud Wellek,ibid.: 148). Y Goldsmith, en An Inquiriy into the Present State of Polite Learning (1759), solicita que "el gusto inglés, al igual que la libertad inglesa, estuviese refrendado tan sólo por las leyes de su propia iniciativa". Es, además, función de la crítica, según Goldsmith, "comprender la naturaleza del medio y del país, etc., antes de dar reglas para dirigir el gusto. En otras palabras: cada país ha de tener un sistema nacional de crítica" (Ibid.).

El medio ambiente cobra una especial relevancia. En una carta a John Brown, fechada en febrero de 1763, Thomas Gray asocia la imaginación con las frías montañas de Escocia (Ibid.: 149). Otro tanto haria el obispo Lowth en De sacra poesi Hebraorum, explicando algunas imágenes de la Biblia en intima conexión con el paisaje de Palestina. Se llegó incluso a investigar el posible emplazamiento de la antigua Troya para analizar las obras de Homero. Así lo hizo Robert Wood en An Essay on the Original Genius and Writings of Homer (1769).

Las condiciones políticas se consideraron también muy importantes a la hora de explicar las obras literarias. Ya hemos visto cómo algunos intelectuales ilustrados insisten en la necesidad de libertad para el desarrollo de las artes y las letras. La frase de Lord Kames "El buen gusto no puede florecer largo tiempo bajo el despotismo" representa muy bien esta nueva posición (apud Wellek, ibid.).

El primitivismo fue también consecuencia del creciente interés por la historia literaria nacional. Amparado en la creencia de que la poesía crece mejor en las sociedades primitivas, trajo consigo la interpretación de Homero como poeta primitivo (Thomas Blackwell) y el descubrimiento de Ossian (Hugh Blair). William Duff expresaria su entusiasmo por Homero y Ossian en Essay on Original Genius (1767), convencido de que los "periodos primitivos e incultos de la sociedad" son "peculiarmente favorables para el desarrollo del genio poético" (apud Wellek, ibid.: 150). Se consideró también a veces como primitiva la literatura isabelina. Así lo hizo Thomas Warton en 
On the Golden Age of Queen Elizabeth (1759). Wellek apunta la confusión existente en la época en torno a las sociedades primitivas; "Todas eran consideradas como si fuesen la misma: los albores de la civilización griega, la sociedad pintada en el Antiguo Testamento, la contemporánea árabe, la feudal de la Edad Media, y aun los tenebrosos tiempos en los que se creía que había vivido Ossian" (lbid.). Señala además a Thomas Percy como el primero que potenció la creencia en la unidad de la poesía primitiva planeando una coleccion titulada Specimes of the Ancient Poetry of Different Nations en donde las traducciones del chino se altemarían con El Cantar de los Cantares. Sus Reliques of Ancient English Poetry (1765) contienen baladas y composiciones líricas del periodo isabelino, romances moriscos e incluso novelas caballerescas. Thomas Gray también concibió una historia de la poesía inglesa que dedicaría gran espacio a los primitivos, aunque no llegó a realizarla.

La evolución de la poesía fue otro motivo de disquisiciones en este periodo. John Brown intentó trazar un esquema evolutivo en Dissertation on the Rise, Union and Power, the Progressions, Separations and Corruptions of Poetry and Music (1763), basado en el encumbramiento de la poesía primitiva. El verso fue, según Brown, anterior a la prosa, porque "la pasión natural por la melodía y la danza imprime necesariamente al acompañamiento del canto el cotrespondiente ritmo" (apud Wellek, ibid.: 151). En un principio, la poesía seria una mezcla de todos los géneros: "mezcolanza extática de himnos, historias, fábula y mitología" (lbid.: 152). Primero surgiria la lírica, las odas y los himnos, "arrebatadas exclamaciones de alegría, pena, triunfo o exaltación" (Ibid.) Luego aparecería la épica y, después, la dramática. Para este esquema, Brown se basa en la literatura griega, aunque trata también de aplicarlo a la literatura hebraica y a la ossiúnica. El proceso de fragmentación descrito por Brown es en realidad un proceso de degeneración gradual de aquella ideal unión primigenia, provocado por una supuesta decadencia de las costumbres. Contra el Renacimiento, que es el momento en el que la poesía se divorcia de la música, lanza Brown sus dardos mús afilados. En cuanto a los intentos contemporáneos de unir de nuevo música y poesía (la ópera, por ejemplo), Brown los desestima acusíndolos de imperfección. Sólo acepta las odas de Dryden con acompañamiento musical. Esto es lo único que salva de la literatura inglesa de la época. La teoría de Brown fue reformulada por Adam Ferguson en Essay on the History of Civil Society (1767). El proceso evolutivo de la literatura viene dado, según Ferguson, por una progresiva división del trabajo (lbid.: 152). Una posición similar adoptaron también Joseph Warton y Richar Hurd. Joseph Warton, en Essay on Pope (1756-1782), sostiene que la poesía ha de expresar los sentimientos de su época. A él le ha tocado vivir en un período de declive imaginativo, en el que la poesia sublime (trágica y épica) de un Shakespeare, un Milton o un Spenser ya no es posible. Por eso, Pope no podría escribir ni poesía dramá- 
tica ni épica. Se habría de contentar con la didáctica y la descriptiva, las más apropiadas al declive de la imaginación. Warton establece, por tanto, una jerarquía de géneros -los más sublimes y perfectos son la tragedia y la épica-y de escritores: Shakespeare, MiIton y Spenser son para él los grandes autores ingleses, los únicos sublimes, los poetas de la pasión, mientras que Pope sólo es un hombre de buen sentido, el poeta de la razón. La poesía de los primeros será, según Warton, poesía pura. La de Pope se quedará simplemente en lo satírico-moral (1bid.: 153-154). Las Letters on Chilvary and Romance de Richard Hurd contiene un planteamiento similar: frente a "la más grande poesía, que puede ser Ilamada poesía pura" de Spenser y Milton, habría "especies más humildes de poesía, especialmente la satírica y moral" de Dryden y Pope (apud Wellek, Ibid.: 154). La influencia de Hurd y de Joseph Warton se percibe en la que seria la primera historia de la literatura inglesa de cierta importancia: la History of English Poetry de Thomas Warton (1774-1781). Warton cree que el progreso de la civilización ha traído consigo una pérdida de la imaginación en favor de la razón, el sentido crítico y la ciencia. De acuerdo con ello, distingue tres fases en la poesía inglesa: imaginación, imaginación y razón sintetizadas, y razón. A la primera pertenecería la obra de Chaucer. La segunda correspondería al período isabelino, y la tercera al siglo XVIIl. Aunque para Warton, como para sus predecesores, este proceso es un proceso degenerativo -la muerte de la poesía a manos de la razón-, confia en que pueda invertirse y aspira a una síntesis de buen gusto e imaginación similar a la que protagonizaron los escritores del período isabelino, con Milton a la cabeza (Ibid.: 155-157).

\section{La retórica}

\subsection{Philosophy of Rhetoric de George Campbell}

La primera edición de la Philosophy of Rhetoric de George Campbell (1709-1796) apareci6 en 1776. Se convirtió pronto en el manual más usado en la enseñanza al menos hasta 1870 aproximadamente. De hecho, se la ha considerado como el tratado de retórica más importante del XVIIl, con mayor profundidad que el de Blair (Corbett, 1971: 623).

La intención de Campbell, según declara en la introducción, es hallar los fundamentos de la retórica a partir del estudio de la naturaleza humana. Es el objetivo de un intelectual neoclásico, empeñado, como todos, en deducir de la experiencia los patrones universales de conducta. Para ello se apoya en cuatro principios: la naturaleza es el modelo del comportamiento humano, la observación debe guiar toda crítica artística, los procedimientos literarios se juzgan de acuerdo con los efectos que provocan en los oyentes y cada discurso debe adaptarse a la situación en que se pronuncia. Distingue además 
las siguientes finalidades en la retórica: "to enlighten the understanding, to please the imagination, to move the passions, or to influence the will" (apud Corbett, ibid.). Esta concepción procede de Cicerón, para quien las funciones de la retórica son enseñar, persuadir y deleitar. Campbel propone ademảs que la lógica sea considerada un mero instrumento de la retórica, invirtiendo así la teoría aristotélica.

\subsection{Las Lectures on Rhetoric and Belles Lettres de Hugh Blair: un exce- lente compendio de la estética ilustrada}

Las Lectures on Rhetoric and Belles Lettres del escocés Hugh Blair ha sido uno de los tratados retóricos más influyentes durante el siglo XVIII y el $\mathrm{X} 1 \mathrm{X}$. Se publicó en 1783 y desde entonces se ha reeditado en infinidad de ocasiones. Ha sido también traducido a distintas lenguas. En España, José Luis Munárriz lo tradujo con el título Lecciones sobre la Retórica y las Bellas Letras por Hugo Blair en 1798-1801. La traducción se convirtió en la guía estética del grupo salmantino, integrado por el propio Munárriz, Jovellanos, Sánchez Barbero y Quintana (Navas Ocaña, 1999a).

Las Lectures on Rhetoric fueron inicialmente unos apuntes para las clases que Blair impartió en la Universidad de Edimburgo desde 1759 y durante veinticinco años. No tenían por tanto ninguna pretensión de originalidad. De ahí que a menudo Blair se limitase a resumir las ideas de Addison, el Dr. Gérard, David Hume, lord Kames y sobre todo Edmund Burke, de quien tomó incluso los ejemplos que ilustraban cada una de las teorías. Menéndez Pelayo le otorga, sin embargo, el mérito de "haber sustituido por principios generales de gusto, los preceptos técnicos y rutinarios de los antiguos retóricos" (1883-1891, I: 1057), aunque en esta labor le habían precedido evidentemente Burke, Kames, Gérard, etc.

El plan de la obra, de acuerdo con la traducción de Munárriz, es el siguiente. El primer volumen contiene algunas reflexiones sobre el gusto, el genio, la belleza, lo sublime, el lenguaje y el estilo. En el segundo hay un amplio espacio para las figuras e incluye una breve historia de la elocuencia con especial atención a Demóstenes y a Cicerón. El volumen tercero está dedicado en su mayor parte de nuevo a la elocuencia, pero también se ocupa de la historia y de los escritos filosóficos, e inicia ya el estudio de los géneros poéticos, en concreto de la poesía pastoral y la lírica. El último volumen se detiene en la poesía didáctica, la descriptiva y la que Blair llama hebraica, para continuar con la épica y los géneros dramáticos (tragedia y comedia).

Quizás la parte más interesante sea la dedicada al gusto, el genio, la critica, la belleza y lo sublime, aunque, como indicábamos antes, Blair no es original, se limita a recoger las ideas de otros teóricos contemporáneos, pero las expone con gran claridad y siempre añade una explicación práctica. 
Quizás en esto se haya basado su éxito editorial (Hernández Guerrero y García Tejera, 1994: 130).

El gusto lo define como "un sentido interno de la belleza, natural a los hombres; y que en su aplicación a objetos particulares puede ser guiado y esclarecido por la razón" (1783, I: 38) ${ }^{13}$. No es, por tanto, un principio arbitrario. Como buen ilustrado, Blair le otorga a la razón un papel fundamental. Además, el gusto de cada individuo debe regirse por el sentido común universal, por la naturaleza común de los sentimientos en el ser humano: "Es preciso que se tenga por bello, aquello que admira el mayor número de hombres: es preciso que se tenga por exacto y verdadero el gusto, que coincide con el modo de pensar más común entre ellos" (lbid.).

En cuanto a la crítica, no es sino "la aplicación del gusto y del buen sentido a las bellas artes" (Ibid.: 46). Pretende "distinguir en cualquiera obra lo bello de lo defectuoso; ascender de casos particulares a principios generales; y de este modo formar reglas para juzgar de las diversas especies de bellezas en las obras de ingenio" (lbid.). Ahora bien, esas reglas proceden de la observación, no son principios a priori fundados en la autoridad. Esta idea es una de las características más señaladas del período ilustrado respecto al clasicismo del XVII. Se siguen acatando las reglas, pero éstas no dependen tanto del principio de autoridad como de la razón y la experiencia: "Las reglas de la crítica no se forman, como suele decirse, por una inducción a priori; esto es, por una especie de raciocinios abstractos e independientes de los hechos y observaciones. La crítica es un arte que se funda enteramente en la experiencia; es decir, en la observación de aquellas bellezas que más se acercan al modelo establecido; de aquellas bellezas que más agradan generalmente al linaje humano" (lbid.: 47)

De todas formas, Blair acudirá para ilustrar esta idea a un ejemplo de la tradición, a una autoridad tan poderosa como la del mismísimo Aristóteles: "Por ejemplo, las reglas de Aristóteles acerca de la unidad de acción en las composiciones épica y dramática, no son reglas que se descubrieron al principio por un raciocino lógico, y se aplicaron después a la poesía; sino que se tomaron de la príctica de Homero y de Sófocles: y se fundaron en las observaciones del placer que recibimos de la relación de una acción única y entera; superior al que recibimos de la relación đe los hechos sueltos o inconexos" (Ibid.).

Pero, si la crítica establece una serie de preceptos de acuerdo con el gusto y el buen sentido universal, ¿cómo es posible que triunfen, que gusten tanto las obras đe Shakespeare o de Calderón, a menudo transgresoras de esos preceptos? Blair ofrece una curiosa respuesta. En ningún momento le abandona la convicción clasicista de que las reglas son la principal fuente de la exce-

" Cilo en todos los casos por la edición de José Luis Munárriż. (1798-1801). 
Iencia poética. De hecho, si Shakespeare o Calderón han conseguido triunfar en el gusto de la mayoría es por haber respetado y practicado con verdadero acierto algunas de esas reglas. Esta circunstancia ha conseguido hacer olvidar al público la cantidad ingente de errores, vicios e inexactitudes que pueblan los dramas shakespereanos y calderonianos. Es la explicación de un ilustrado que no renuncia en ningún momento a sus firmes convicciones: "Convengo en que hay obras, que contienen transgresiones palpables de las Ieyes de la crítica; y que se han granjeado, sin embargo, una admiración general, que aún dura. Tales son los dramas de Shakespeare y Calderón: los cuales considerados como composiciones dramáticas son sumamente irregulares. Pero debemos advertir, que estas obras se han granjeado la admiración pública, no por las transgresiones de las reglas del arte, sino a despecho de tales transgresiones: que poseen otras bellezas conformes a las reglas más exactas: y que la fuerza de estas bellezas es tal, que ha sofocado todas las censuras; y da al público un grado de complacencia superior al disgusto que le ocasionan sus defectos. Shakespeare agrada; no por amontonar en un drama sucesos de muchos años; no por sus mezcolanzas grotescas de tragedia y comedia en una misma pieza; no por los pensamientos violentos y afectados goticismos que emplea algunas veces, y que al paso miramos como lunares, los achacamos a la edad en que vivió; sino por sus animadas y clásicas representaciones de caracteres, por la viveza de sus descripciones, la energía de sus sentimientos, y por poseer en grado superior el verdadero lenguaje de la pasión; bellezas que la sana crítica nos enseña a apreciar en el mismo grado que la naturaleza a sentirjas" (Ibid.: 50-51). Obsérvese la insistencia de Blair en el 'lenguaje de la pasión', al igual que hiciera John Dennis.

La distinción de Blair entre genio y gusto también me parece interesante: "El gusto consiste en la facultad de juzgar; el genio en la facultad de ejecuIar" (Ibid.: 52). Y añade: "Un gusto refinado hace un buen crítico: pero se necesita genio para ser poeta u orador" (Ibid.). El genio es un don natural que no todo el mundo posee, aunque "puede sin duda aumentarse mucho por el arte y el estudio: pero no puede adquirirse por ellos solos" (Ibid.: 53). Se trata de una idea clásica de larguísima tradición, cuya formulación más conocida es la célebre dualidad horaciana ingenium / ars.

Al ocuparse de lo sublime, Blair sigue a Plotino: es "una cosa que eleva el ánimo" (Ibid:: 75). Ahora bien, cuando ofrece ejemplos de literatura sublime, y aunque entre esos ejemplos figuran autoridades clásicas de la talla de Homero, Blair recurre también a la figura de Ossian y anuncia así el gusto por la literatura primitiva que caracterizará al romanticismo"19: "Las obras de

"De todas formas, Homero estaba siendo considerado cada vez más no una autoridad clásica sino un poeta primitivo, sobre todo después de la obra de Thomas 
Ossian (...) están llenas de ejemplos sublimes. Los asuntos de este autor, y el estilo en el que escribe, son muy a propósito para ello. Posee enteramente la sencilla y venerable manera de los tiempos antiguos. No abunda de adornos superfluos o afectados, pero esparce sus imágenes con una rápida concisión, que le pone en estado de herir el ánimo con la mayor fuerza. En los poetas de tiempos más cultos buscamos las gracias de un escrito correcto, la justa proporción de las partes, y que la narración esté conducida con arte. Lo alegre y lo bello aparecerá sin duda con más ventajas en medio de unas escenas risueñas, $y$ en unos asuntos placenteros: pero el sublime se encuentra, como en su centro, en medio de las rudas escenas de la naturaleza y de la sociedad, tales como las que describe Ossian, entre rocas y torrentes, y entre huracanes y batallas" (Ibid.: 83).

Obsérvese cómo el concepto que Blair tiene de lo sublime, además de coincidir con el plotiniano, se sitúa en el origen de la estética romántica de la naturaleza y de la veneración romántica por los autores primitivos.

La descripción de los principales géneros literarios ocupa un amplio espacio en las Lectures on Rhetoric, aunque adolece de 'consistencia metodológica' por falta de principios clasificatorios (Wellek, 1954-1996, I: 139). Aparece, por ejemplo, una 'poesía hebraica', la de las Sagradas Escrituras, que en realidad 'poco tiene de género'. Junto a ella se estudian la pastoril, la lírica, la descriptiva y la didáctica. Incluye, por supuesto, la épica y la dramática, de acuerdo con las teorías aristotélicas. Como buen neoclásico, Blair recomienda el respeto escrupuloso de las tres unidades (acción, tiempo y lugar ${ }^{20}$. La novela aparece, no entre los géneros poéticos, sino como 'histo-

Blackwell Enquiry into the Life and Writings of Homer (1735). Fue esta "la primera tentativa (...) de interpretar a Homero con independencia de las tradicionales reglas épicas, como representante de su tiempo y de su sociedad" (Wellek, 1954-1996, I; 144). En Critical Dissertation on the Poems of Ossian (1763), Blair ya habia señalado que Ossián por la "elevación de las pasiones" estaba a la altura de Homero y de Virgilio, aún reconociendo que carecía de la "dignidad narrativa" de los autores clásicos. Como apunta Wellek, "esta cautela de Blair en la comparación fue pronto desechada por muchos aficionados a Ossian, que lo exaltaron por encima de Homero, y a sus licencias líricas, por encima de las venerables concepciones épicas" (Ibid.).

20 "Pero aunque los modernos parezcan exentos de la rígida observación de estas unidades, debemos advertir sin embargo, que no son enteramente libres en esta parte. Las frecuentes y violentas mudanzas de lugar y de tiempo, llevando atropelladamente al espectador de un lugar a otro distante, o haciendo que se pasen días, semanas, y aun años en el discurso de la representación, son libertades que ofenden a la fantasia, y dan a la obra un aire romancesco: por lo que no puede permitirse al escritor dramático que aspire a la correcctón. En particular debemos tener muy presente, que sólo entre acto y acto puede tomarse alguna libertad de salir de las unidades de lugar y tiempo. 
ria ficticia' junto a la historia, los diálogos filosóficos y las cartas. En el ciclo clasicista, los géneros no contemplados por Aristóteles hacen vacilar a los tratadistas y, si se deciden a incluirlos, sus propuestas suelen ser tan curiosas como la de Blair. Ahora bien, Blair trata el género con cierta simpatía y le reconoce algunos méritos fundamentalmente didácticos ${ }^{21}$. Intenta además establecer su origen y señalar sus hitos más importantes. Según Blair, las primeras manifestaciones narrativas habria que buscarlas en la India y en los cuentos jonios y milesios. Le sigue la literatura romana con Apuleyo al frente. En la Edad Media la tradición se mantiene viva gracias a los romances de caballerias (Amadís de Gaula, Orlando, etc.), que al menos "Tuvieron el mérito de estar escritos con una moral muy elevada y heroica" (Ibid., III: 293). Después vino el 'romance heroico', en el que perduran los ideales elevados pero desaparecen los dragones, los castillos encantados, etc. (Ibid.: 295). Y por fin surge la 'novela familiar' contemporánea (Ibid.). Blair le dedicará una gran atención a la Pamela de Richardson.

\subsection{Otras retóricas de la época}

A System of Rhetoric (1733) de John Stirling destaca por su brevedad y su didactismo. Alcanzó gracias a ello gran popularidad. Dedica un amplio espacio a las figuras y tropos ( 97 en total) constituyendo uno de los mejores catálogos de la época junto con The Art of Rhetoric (1739) de John Holme. Lectures Concerning Oratory (1758) de John Lawson se inspira en fuentes clásicas, sobre todo la retórica aristotélica, pero el mejor compendio de las teorías retóricas de la Antigüedad fue A System of Oratory (1758) de John

En el discurso de cada acto deben observarse éstas con rigor, es decir, que durante el acto debe continuar la misma escena; y no ha de pasar más tiempo, que el que se gasta en la representación de aquel acto. Esta es una regla que los franceses observan regularmente, Quebrantar estat regla, como lo hacen a menudo españoles e ingleses, cambiar de lugar y mudar la escena en medio del acto, es mucha incorrección; y destruye todo el designio de la división del drama en actos" (Blair, 1783, IV: 230).

${ }^{21}$ "Resta tratar de otra especie de composición en prosa; la cual comprehende una numerosísima, y en general poco importante clase de escritos, conocidos con el nombre de romances y novelas. Éstas pueden parecer a primera vista demasiado fútiles para dar de ellas una noticia particular. Pero yo no pienso de este modo (...) En efecto, se puede hacer uso de las historias ficticias para varios fines, y todos ellos muy útiles. Ellas son unos de los mejores canales para comunicar la instrucción, para pintar la vida y las maneras de los hombres, para mostrar los yerros a que nos amastran nuestras pasiones, y para hacer amable la virtud y odioso el vicio. Todo esto se consigue mejor con historias bien imaginadas, que por medio de una instruccion sencilla y desnuda" (Ibid., III: 289-290). 
Ward. En cuanto a Lectures on Elocution (1762) de Thomas Sheridan y Elements of Elocution (1781) de John Walker, se centran en figuras y tropos (Corbett, 1971:618-625).

\section{Recapitulación}

Con la Ilustración, el principio de autoridad será a menudo desbancado en favor de la razón, la naturaleza, y, a veces, de la libertad. En Shaftesbury, Addison o Pope el genio natural prevalecerá sobre el arte, llegando incluso a alcanzar con Young un carácter sobrenatural que anuncia el romanticismo. Shakespeare se convierte gracias a Pope en el genio natural por excelencia. Y esto traerá consigo el rechazo de las uniđades dramáticas (Samuel Johnson, Lord Kames, etc.). Por la misma razón se revalorizan géneros no contemplados en la preceptiva clasicista como la novela (Blair, Reeve, Moore) y se recuperan ciertos poemas épicos, los de Ariosto, Tasso o Spenser, que transgreden esa preceptiva (Warton, Hurd). Gracias a ellos una nueva mitología (Ossian, los magos y brujas medievales), que será definitivamente encumbrada por la literatura romántica, sustituye a la grecolatina. Además, Shaftesbury, Hume y Lord Kames apuntan la necesidad de libertades políticas para el florecimiento de las artes y las ciencias, expresando asi la aspiración burguesa a un espacio discursivo propio, racional e ilustrado, al margen del Estado absolutista.

Por otra parte, Hogart, de acuerdo con un elemento de la naturaleza $-\mathrm{el}$ ojo-, dirá que la línea ondulada es la línea por excelencia de la belleza. Y Johnson esgrimirá el realismo como uno de sus más importantes principios críticos. De todas formas, el tópico Ut pictura poesis ya es discutido por Burke, anticipándose al célebre Laocconte de Lessing, y por Lord Kames. Se intenta así rebatir el carícter imitativo de la poesía, que con Reynolds adquiere una formulación especial -la realidad idealizada-, y que John Dennis socavaría muy pronto, en 1706, con su célebre teoría de la pasión. El componente emocional de la poesía adquirirá ahora un gran relieve, sobre todo en las teorias primitivistas (Duff, Warton, Percy, Blair), germen del historicismo (Brown, Ferguson, Joseph y Thomas Warton). Su consecuencia inmediata serí un creciente interés por la lírica (Lowth, Webb y Jones). El auge del sentimiento se deja notar también en el ámbito de la crítica con el crítico artista de Pope, la simpatía de Adam Smith, la simpatia enajenada de Alison y la critica del inconsciente de William Blake.

Pero quizás la nota característica de la estética ilustrada sea la problemática del gusto y el sentido común. Algunos teóricos sostienen que la belleza es una cualidad de los objetos (Addison, Hogart, Burke), mientras otros creen que es algo propio de la mente que los contempla (Hume). Ahora bien, en ambos casos el sentido común funcionará como freno al subjetivismo ra- 
dical, previsible en concepciones como la de Hume. Todos ellos se aplicarán en la búsqueda de las normas del gusto y con frecuencia recurrirán a la tradición, a la autoridad de los siglos, cuando no les queden más recursos (Gerard, Blair). Preferirán, no obstante, analizar racionalmente aquello que origina en el ser humano la idea de lo bello. En ese contexto se integran sus disquisiciones sobre la sublimidad, la belleza y la novedad (Addison, Burke, etc.). Sin ellas, y en particular sin las teorías ilustradas sobre lo sublime difícilmente podría entenderse la desmesura de las pasiones románticas.

En cuanto al desinterés estético, tanto Hutcheson como Adam Smith pondrán las bases de las doctrinas del arte por el arte y lo harán curiosamente a partir de una concepción moralista del hecho literario. Así se explica la continuidad, nunca rota del todo, entre el ciclo clasicista y las nuevas incitaciones del siglo XIX, fraguadas en su mayoría, como hemos visto, por el pensamiento ilustrado.

\section{REFERENCIAS BIBLIOGRÁFICAS}

ABRAMS, M. H. (1953). El espejo y la lámpara: teoria romántica y tradición crítica. Barcelona: Seix Barral, 1975.

ADDISON, Joseph (1712). Sobre los placeres de la imaginación. Trad. José Luis Munárriz. Variedades de Ciencias, Literatura y Artes, III, 1804.

ÁLVAREZ BARRIENTOS, J. (1991). La novela del siglo XVIII. Gijón: Júcar.

ATKINS, John William Hey (1950). English Literary Criticism: 17 th and 18th centuries. London: Methuen.

BARNARD, John (ed.) (1973). Pope: the Critical Heritage. London: Routledge \& Kegan Paul.

BAYER, Raymond (1961). Historia de la estética. México: Fondo de Cultura Económica, 1993.

BEGUIRISTÁIN, María Teresa (1989). "Prólogo". En David Hume (1757). La norma del gusto y otros ensayos. Barcelona: Península, 5-19.

BLAKE, William (1939). Poetry and Prose of William Blake. Ed. Geoffrey Keynes. London \& New York.

- (1971). Poemas proféticos y prosas. Prólogo de Cristóbal Serra. Barcelona. Barral.

- (1974). Visiones. Ed. Enrique Caracciolo. México: Era.

BLAIR, Hugh (1782), Lecciones sobre la Retórica y las Bellas Letras. Trad. José Luis Munárriz. Madrid: Ibarra, 1816-1817.

BOSWELL, James (1989). Life of Samuel Johnson. Chicago: Enciclopedia Británica.

BOULTON, James T. (ed.) (1971). Johnson. The Critical Heritage. London: Routledge and Kegan Paul. 
BOZAL, Valeriano (1985). "Sublime, Neoclásico, Romántico". En Edmund Burke (1757). Indagación filosófica sobre el origen de nuestras ideas acerca de lo sublime y lo bello. Murcia: Colegio Oficial de Aparejadores y Arquitectos Técnicos de Murcia, 7-37.

BROWN, Joseph Epes (ed.) (1961). The Critical Opinion of Samuel Johnson. New York: Russel \& Russell.

BURKE, Edmund (1757). Indagación filosófica sobre el origen de nuestras ideas acerca de lo sublime y lo bello. Ed. Valeriano Bozal. Murcia: Colegio Oficial de Aparejadores y Arquitectos Técnicos de Murcia, 1985 (facsímil de la ed. de Juan Pérez de la Dehesa en Universidad de Alcalá, 1807).

CERECEDA, Miguel (1997). "Prólogo". En William Hogarth (1753). Análisis de la belleza. Madrid: Visor, 1997, 9-21.

CORBETT, Edward P. J. (1971). Classical Rhetoric for the Modern Student. New York: Oxford University Press.

DAMROSCH, Leopold Jr. (1976). The Uses of Johnson's Criticism. Charlottesville: University Press of Virginia.

DIETZ, Bernd (1988). "Introducción". En Samuel Johnson (1779-1781), Vidas de los poetas ingleses. Madrid: Cátedra, 7-46.

EAGLETON, Terry (1984). La función de la crítica. Barcelona: Paiđós, 1999. ENGELL, James (1989). Forming the critical mind: Dryden to Coleridge. Harvard: Harvard University Press.

HARDY, J. P. (ed.) (1971). Johnson's Lives of the Poets. Oxford: Clarendon Press.

- (1979). Samuel Johnson. A Critical Study. London: Routledge and Kegan Paul.

HERNÁNDEZ GUERRERO, José Antonio y GARCIA TEJERA, Maria del Carmen (1994). Historia breve de la retórica. Madrid: Síntesis.

HOGARTH, William (1753). Análisis de la belleza. Ed. Miguel Cereceda. Madrid: Visor, 1997.

HUME, David (1757). La norma del gusto y otros ensayos. Ed. María Teresa Beguiristáin. Barcelona: Península, 1989.

JOHNSON, Samuel (1779-1781). Vidas de los poetas ingleses. Ed. Bernd Dietz. Madrid: Cátedra, 1988.

LAFARGA, Francisco (ed.) (1996). El discurso sobre la traducción en la historia. Barcelona: EUB.

MENÉNDEZ PELAYO, Marcelino (1883-1891). Historia de las ideas estéticas en España. Madrid. C.S.I.C., 1994".

MIRABENT, Francisco (1927). La estética inglesa del siglo XVIII. Barcelona: Cervantes.

NAVAS OCAÑA, María Isabel (1999a). Introducción al estudio de las teorias literarias en España. Almeria: Servicio de Publicaciones de la Universidad de Almería. 
- (1999b). Teoria de la literatura británica y norteamericana. I. De la Antigïedad grecolatina al siglo XIX. Almería: Servicio de Publicaciones de la Universidad de Almería.

POPE, Alexander (1967). Selected Poetry and Prose. Ed. William K. Wimsatt, Jr. New York: Holt, Rinehart and Winston.

REYNOLDS, Joshua (1769-1790), Discourses on art. Ed. Robert R. Wark. New Haven and London: Yale University Press, 1988.

SAINTSBURY, G. E. B. (1901-1904). A History of Criticism and Literary Taste in Europe from the earliest tert to the present day. Tome II; From the Renaissance to the decline of eighteenth century ortodoxy. Genève: Slaktine, 1971.

WAHNÓN, Sultana (199I). Introducción a la historia de las teorias literarias. Granada: Servicio de Publicaciones de la Universidad de Granada.

WAIN, John (ed.) (1973). Joltnson as Critic. London: Routledge and Kegan Paul.

-(1980). Samuel Johnson. London: Macmillam.

WARK, Robert R. (1988). "Introduction". En Joshua Reynolds (1769-1790). Discourses on art. Ed. Robert R. Wark. New Haven and London: Yale University Press, XV-XXXV.

WELLEK, René (1954-1996). Historia de la crítica moderna (I750-1950). I. La segunda mitad del siglo XVIII. Madrid: Gredos.

WIMSATT, William K. Jr. (1967). "Introduction". En Alexander Pope (1967). Selected Poetry and Prose. New York: Holt, Rinehart and Winston, VII-LIV.

- (1968). Philosophic Words. A Study of Style and Meaning in the Rambler and Dictionary of Samuel Jolmson. Hamden, Connecticut: Archon Books.

- (1972). The prose style of Samuel Johnson. Hamden, Connecticut: Archon Books.

WIMSATT, William K. Jr. y BROOKS, Cleanth (1957). Literary Criticism. A short history. I. Classical Criticism y II. Neoclassical Criticism. London: Routledge \& Kegan Paul, 1970. 